\title{
MUSIK SAKEPENG DALAM UPACARA PANGANTEN HAGUET SUKU DAYAK NGAJU DI KOTA PALANGKARAYA KALIMANTAN TENGAH
}

\author{
Kartinus Muda \\ Jurusan Etnomusikologi FSP ISI Yogyakarta
}

\begin{abstract}
Abstrak
Ansambel sakepeng dalam upacara panganten haguet merupakan sebuah prosesi upacara yang sangat penting untuk dilaksanakan, selain bertujuan untuk mengikat kedua calon pengantin menuju kejenjang pernikahan, dilaksanakannya upacara tersebut juga bertujuan untuk memperkenalkan identitas dari persebaran masyarakat Dayak Ngaju. Adapun masyarakat yang masih belum mengetahui apa fungsi ansambel sakepeng dalam upacara panganten haguet dan bagaimana bentuk dan penyajiannya. Maka dari itu penulis bertujuan mencari tahu dan menjawab permasalahan yang terjadi dengan menggunakan metode kualitatif dengan pendekatan etnomusikologis. Hasil penelitian yang didapat yaitu terdapat pengembangan musik sakepeng dengan penambahan beberapa instrumen di dalam ansambel tersebut.
\end{abstract}

Kata Kunci: Musik Sakepeng, Panganten Haguet, Dayak Ngaju.

\begin{abstract}
The sakepeng ensemble in the panganten haguet ceremony is a very important ceremony procession to be carried out, aside from aiming to bind the two bride and groom to the marriage ceremony, the ceremony also aims to introduce the identity of the Dayak Ngaju community. As for the people who still don't know what the function of the sakepeng ensemble in the panganten haguet ceremony is and how it is presented and presented. Therefore the author aims to find out and answer problems that occur using qualitative methods with ethnomusicological approaches. The results obtained are that there is the development of sakepeng music by the addition of several instruments in the ensemble.
\end{abstract}

Keywords: Sakepeng Music, Panganten Haguet, Dayak Ngaju. 


\section{A. Latar Belakang}

Masyarakat Dayak Ngaju merupakan suku yang memegang teguh dalam sebuah prinsip berkehidupan, seperti halnya tertuang pada isi kalimat Belum Bahadat Ruhui Rahayu yang apabila diartikan adalah hidup rukun, bertatakrama, sejahtera dan harmonis. Berangkat dari istilah tersebutlah masyarakat Dayak Ngaju yang kemudian mengaplikasikannya kedalam sebuah prosesi upacara pernikahan yang biasa disebut dengan istilah Panganten Haguet atau Penganten Manda'i. Bagi masyarakat Dayak Ngaju upacara panganten haguet merupakan sebuah prosesi upacara yang sangat penting untuk dilaksanakan, selain bertujuan untuk mengikat kedua calon pengantin menuju kejenjang pernikahan, dilaksanakannya prosesi tersebut juga bertujuan untuk memperkenalkan identitas dari persebaran masyarakat Dayak Ngaju. (Riwut, 2003, hlm.58)

Seiring berkembangnya zaman serta dengan dipengaruhi oleh modernisasi, masyarakat Dayak Ngaju beserta majelis agama Hindu Kaharingan telah bersepakat, bahwa masyarakat Dayak Ngaju yang telah berpindah keyakinan maupun yang masih menganut kepercayaan Kaharingan agar wajib hukumnya untuk melaksanakan upacara panganten haguet, hal tersebut dilakukan guna mempertahankan tradisi yang sudah lama dilakukan oleh para leluhur suku Dayak Ngaju. Adapun dalam pelaksanaan prosesi upacara panganten haguet turut menghadirkan beberapa instrumen didalamnya, yang dimana hadirnya instrumen-instrumen tersebut akan digunakan pada saat iring-iringan calon panganten mempelai pria menuju ke rumah kediaman mempelai wanita, iringan pancak silat pada saat memutuskan lawai (benang) sakepeng, dan iringan pada saat prosesi pencarian panganten wanita.

Ansambel sakepeng merupakan ansambel pengiring dalam prosesi upacara pernikahan suku Dayak Ngaju di Kalimantan Tengah. Ansambel tersebut merupakan ansambel pengiring dalam kegiatan pancak silat, pada upacara panganten haguet. Sebelum rombongan pihak keluarga beserta mempelai pria dapat memasuki halaman rumah mempelai wanita, pintu gerbang sakepeng akan terlebih dahulu dibuka oleh para pemain pancak silat, yang kemudia setelah dibukanya pintu gerbang tersebut barulah mantir adat dari perwakilan mempelai wanita yang mempersilakan rombongan pihak keluarga mempelai pria untuk memasuki halaman rumah mempelai wanita.

Secara bentuk fisik instrumen garantung atau yang biasa disebut dengan gong merupakan instrumen yang memiliki kesamaan seperti instrumen Kempul pada 
gamelan Jawa (Haryanto, 2015, hlm. 53), sedangkan instrumen gandang manca merupakan instrumen perkusi dengan memiliki dua sisi membran kulit mirip seperti gendang Gimba di Palu. Instrumen tersebut dimainkan pada saat mempelai pria beserta rombongan keluarga berangkat menuju ke rumah kediaman keluarga mempelai wanita dengan diiringi ansambel Sakepeng selama proses keberangkatan.

Jumlah pemain pada ansambel sakepeng umumnya hanya melibatkan dua sampai tiga orang saja, akan tetapi berbeda halnya untuk di zaman sekarang jumlah pemain pada ansambel sakepeng kini telah melebihi dari jumlah pakem sebelumnya, dampak hal tersebut tentunnya akan berpengaruh terhadap bentuk dan lagu pada iringan ansambel sakepeng. Selain mengalami perubahan pada bentuk musik, prosesi upacara panganten haguet juga mengalami perubahan dalam segi pelaksanannya. Berangkat dari kegelisahan tersebutlah yang menjadikan peneliti ingin menelaah lebih jauh lagi agar dapat menjawab permasalahan yang terjadi pada prosesi upacara panganten haguet di Palangka Raya.

\section{Konsep Fungsional}

Musik dapat pula dilihat berdasarkan fungsi dan kegunaannya, baik yang sesuai dengan kepentingan sosial, maupun kepentingan individu senimannya masing-masing. Menurut R.M. Soedarsono, seni pertunjukan memiliki 3 fungsi yaitu: (1) sebagai sarana ritual; (2) sebagai hiburan pribadi; dan (3) sebagai presentasi estetis. Ritual dalam kaitannya seni dengan sebuah keyakinan dan kekuatan gaib atau makhluk yang kasat mata sebagai penikmatnya, hiburan dalam arti sebuah pertunjukan dengan tujuan sebagai sarana untuk menghibur diri sediri dan seni pertunjukan sebagai presentasi estetis adalah sebuah pertunjukan yang dalam menikmatinya, memerlukan materi/uang sebagai alat tukar dengan materi pertunjukan yang akan dinikmatinya (RM Soedarsono, 2002: 123).

Sementara itu, menurut Alan P. Merriam, musik memiliki 10 fungsi, yaitu: (1) fungsi pengungkapan emosional; (2) fungsi penghayatan estetis; (3) fungsi hiburan; (4) fungsi komunikasi; (5) fungsi perlambangan; (6) fungsi reaksi jasmani; (7) fungsi yang berkaitan dengan normanorma sosial; (8) fungsi pengesahan lembaga sosial; (9) fungsi kesinambungan kebudayaan; dan (10) fungsi pengintegrasian masyaraka(Alan $\mathrm{P}$. Merriam, 1964: 219-226). Teori fungsi, baik yang dikemukan oleh Merriam maupun Soedarsono ini pada dasarnya dapat digunakan sebagai dasar teoretis untuk melihat fungsi musik (seni) dalam konteks kehidupan masyarakat Jawa Barat di Yogyakarta. 


\section{B. Metode Penelitian}

Penelitian akan menggunakan metode penelitian kualitatif, peneliti kualitatif dituntut dapat menggali data berdasarkan apa yang diucapkan, dirasakan, dan dilakukan oleh partisipan atau sumber data. Penelitian kualitatif harus bersifat "perspektif emic" artinya memperoleh data

\section{Hasil dan Pembahasan}

\section{Fungsi Ansambel Sakepeng Dalam} Upacara Panganten Haguet

Ansambel sakepeng merupakan ansambel pengiring dalam prosesi pelaksanaan upacara panganten haguet pada suku Dayak Ngaju. Kehadiran ansambel tersebut merupakan satu kesatuan dalam pelaksanaan prosesi upacara panganten haguet yang tidak bisa dipisahkan. Adapun fungsi ansambel sakepeng dalam upacara panganten haguet adalah sebagai sarana pengiring prosesi arak-arakan mempelai pria menuju ke rumah kediaman mempelai wanita, mengiringi prosesi pemutusan lawai sakepeng, dan prosesi dalam pencarian mempelai wanita.

Adapun dalam buku R.M. Soedarsono yang menjelaskan bahwa seni pertunjukan di Indonesia memiliki fungsi primer dan fungsi sekunder. Berdasarkan pendapat tersebut maka fungsi ansambel sakepeng dalam upacara panganten haguet terbagi bukan sebagai mana seharusnya, bukan berdasarkan apa yang dipikirkan oleh peneliti, tapi berdasarkan sebagaimana adanya yang terjadi di lapangan, yang dialami, dirasakan, dan dipikirkan oleh partisipan/sumber data (Sugiyono, 2012, hlm.212).

menjadi dua bagian yaitu, fungsi primer dan fungsi sekunder. Berikut beberapa penjelasan tentang fungsi dalam pelaksanaan upacara panganten haguet.

\section{Fungsi primer}

\section{a. Ansambel Sakepeng Sebagai Sarana Ritual}

upacara panganten haguet merupakan sebuah prosesi upacara pernikahan yang sangat penting untuk dilaksanakan selain bertujuan untuk mengikat kedua calon pengantin menuju kejenjang pernikahan, dilaksanakannya prosesi tersebut juga bertujuan untuk memperkenalkan identitas dari persebaran masyarakat Dayak Ngaju. Adapun dalam pelaksanaan upacara panganten haguet ditentukan dengan ketentuan sebagai berikut; (1) tempat pelaksanaan upacara panganten haguet; (2) waktu pelaksanaan upacara panganten haguet; (3) sesajien sebagai syarat dalam pelaksanaan upacara panganten 
haguet; (4) pelaku dalam hal ini merupakan pemimpin dalam pelaksanaan upacara panganten haguet; (5) kostum sebagai penguat identitas dari suatu kelompok.

\section{b. Ansambel Sakpeng Sebagai Sarana Hiburan}

Keberadaan ansambel sakepeng dalam prosesi upacara panganten haguet merupakan salah satu serangkaian yang tidak dapat dipisahkan, tahapantahapan yang melibatkan adanya ansambel tersebut menjadikannya suatu sarana hiburan bagi kalangan masyarakat Dayak Ngaju seperti halnya pada prosesi arak-arakan mempelai pria, pemutusan lawai sakepeng, sampai pada prosesi pencarian mempelai wanita, jadi dapat disimpulkan bahwa keberadaan ansambel sakepeng menjadi salah satu fungsi sarana hiburan dalam pelaksanaan upacara panganten haguet.

\section{Fungsi Sekunder}

a. Ansambel Sakepeng Sebagai Sarana Komunikasi

Musik dapat berfungsi sebagai sarana komunikasi apa bila di dalam musik tersebut terdapat suatu pesan atau arti yang ingin disampaikan melalui pelaku kepada pendengar. Seperti halnya pada musik ansambel sakepeng yang dimana melodi, ritme, dan tempo pada setiap pola yang diiringi ansambel sakepeng memiliki arti dan tujuan tersendiri.

\section{b. Ansambel Sakepeng Sebagai}

\section{Identitas Masyarakat}

Keberadaan ansambel sakepeng dalam pelaksanaan upacara panganten haguet merupakan salah satu ciri khas tersendiri yang dimiliki oleh kalangan masyarakat Dayak Ngaju. Dalam hal ini upacara panganten haguet yang dimana merupakan wariskan turuntemurun leluhur suku Dayak Ngaju sehingga menjadikanya sebuah ciri khas tersendiri bagi masyarakat luas.

\section{Bentuk Penyajian Ansambel} Sakepeng dalam Upacara Panganten Haguet

1. Urutan-Urutan Penyajian dalam Upacara Panganten haguet

\section{1) Arak-Arakan Mempelai Pria}

Pola Tabuhan Musik Sakepeng (arakarakan), tempo 100 dengan sukat 3/4. Adapun notasi sebagai berikut:

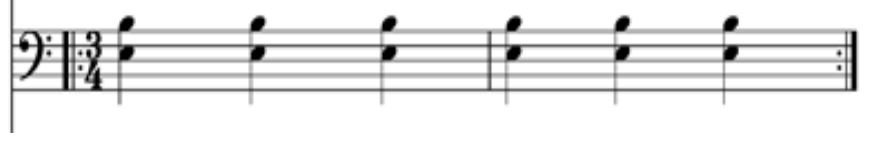




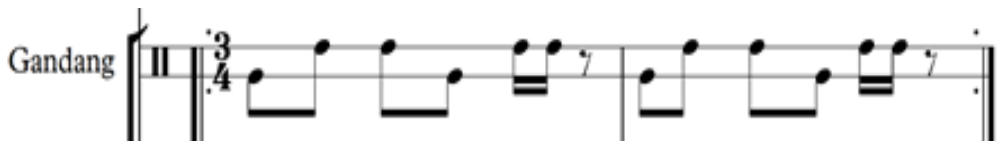

\section{2) Sakepeng (Pancak Silat)}

Pola Tabuhan Musik Sakepeng, tempo 100 dengan sukat 3/4.

Musik Sakepeng

Adapun notasi sebagai berikut:
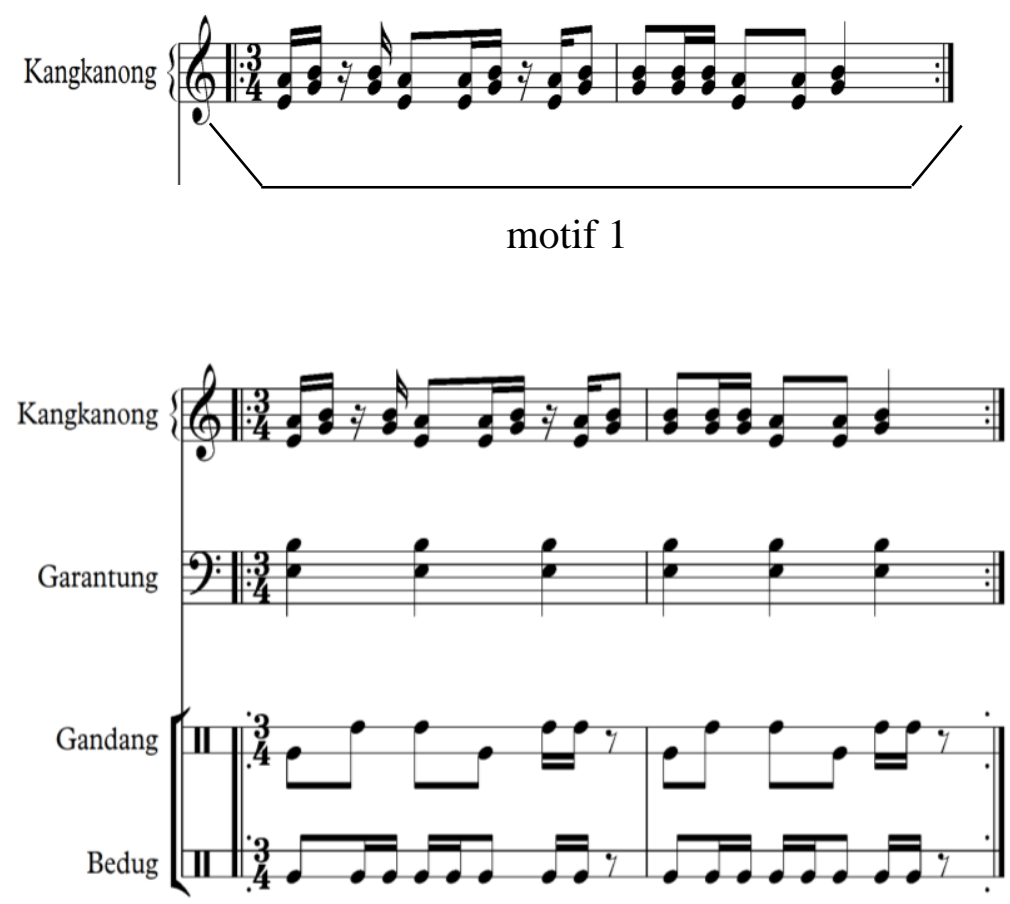

\section{3) Tari Penyambutan}

Pola Tabuhan Musik Bahalai I, tempo 100 dengan sukat 4/4.

Musik Bahalai I melodi kangkanong.

Adapun notasi sebagai berikut:

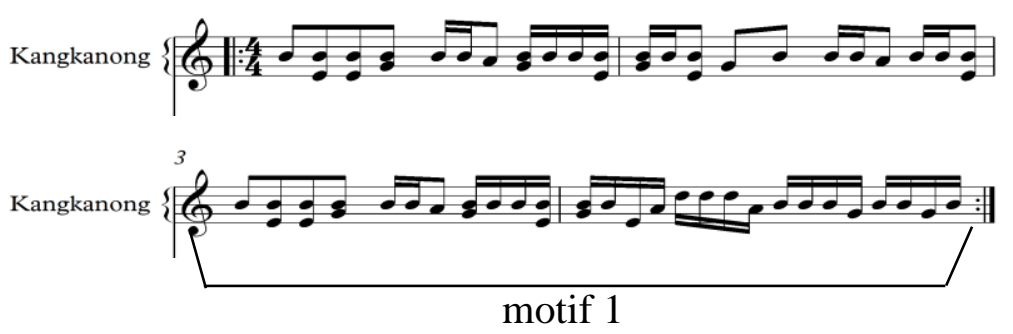



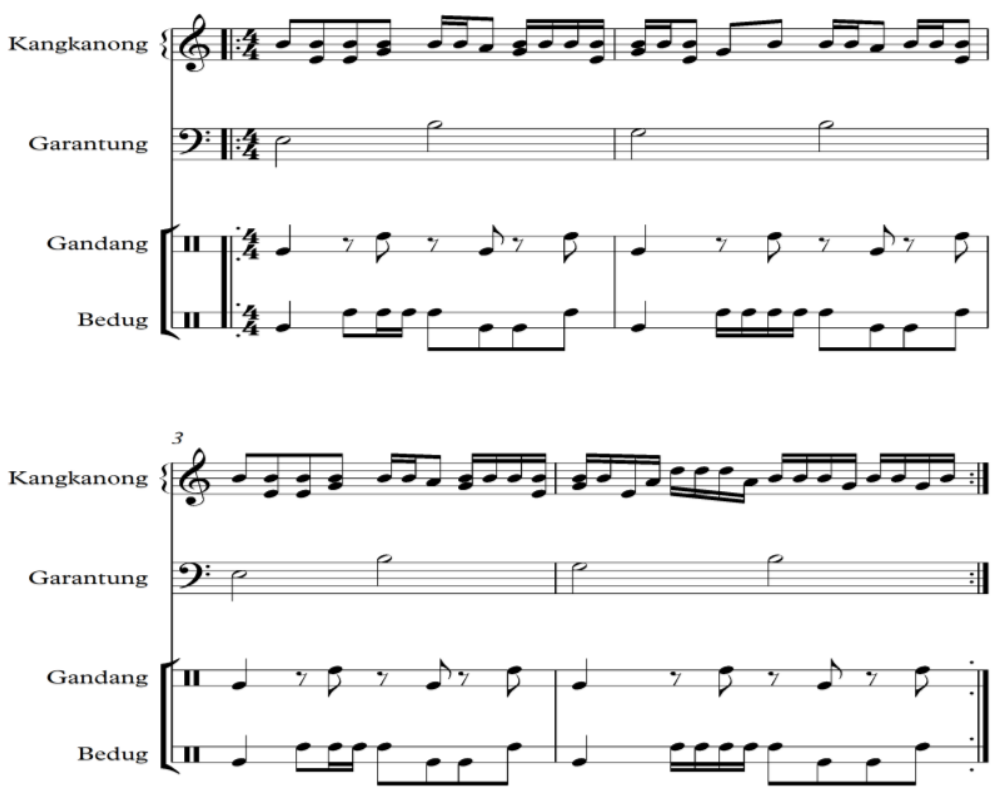

\section{4) Mamapas}

Mamapas merupakan sebuah prosesi pembersihan secara simbolis yang bermakna agar penganten, rumah, dan lingkungan tempat dilaksanakannya upacara panganten haguet dapat bersih dari segala hal-hal yang bersifat tidak baik, yang dimana masyarakat suku Dayak Ngaju menyebut roh jahat tersebut dengan istilah Pali Endus Dahiang Baya.

\section{5) Palaku (seserahan)}

Nagih syarat adalah sebuah prosesi yang dimana mempelai pria harus memenuhi syarat berupa tujuh belas poin yang dimana poin-poin tersebut tentunya sudah ditentukan oleh pihak mantir adat. Setelah tujuh belas poin tersebut sudah terpenuhi, maka pihak dari keluarga mempelai pria akan menagih balik atas haknya yaitu, mengambil mempelai wanita yang sudah ditentukan untuk menjadi istri dari calon mempelai pria.

\section{6) Mencari Pengantin Wanita}

Pola Tabuhan Musik Bahalai II, tempo 100 dengan sukat 4/4.

Musik Bahalai II melodi kangkanong. Adapun notasi sebagai berikut:

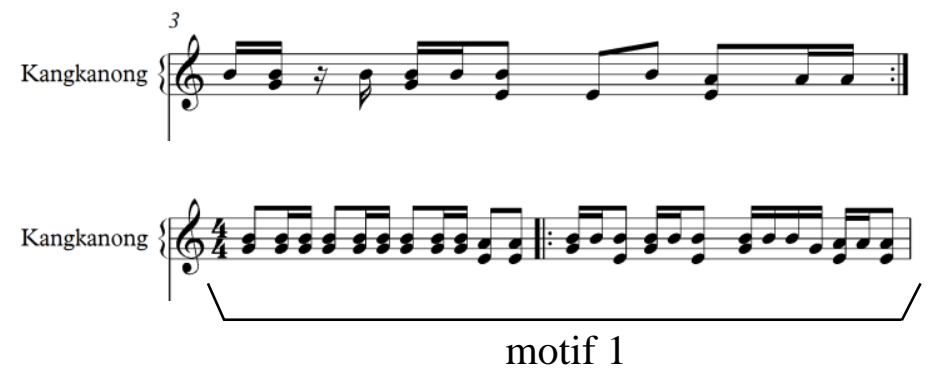




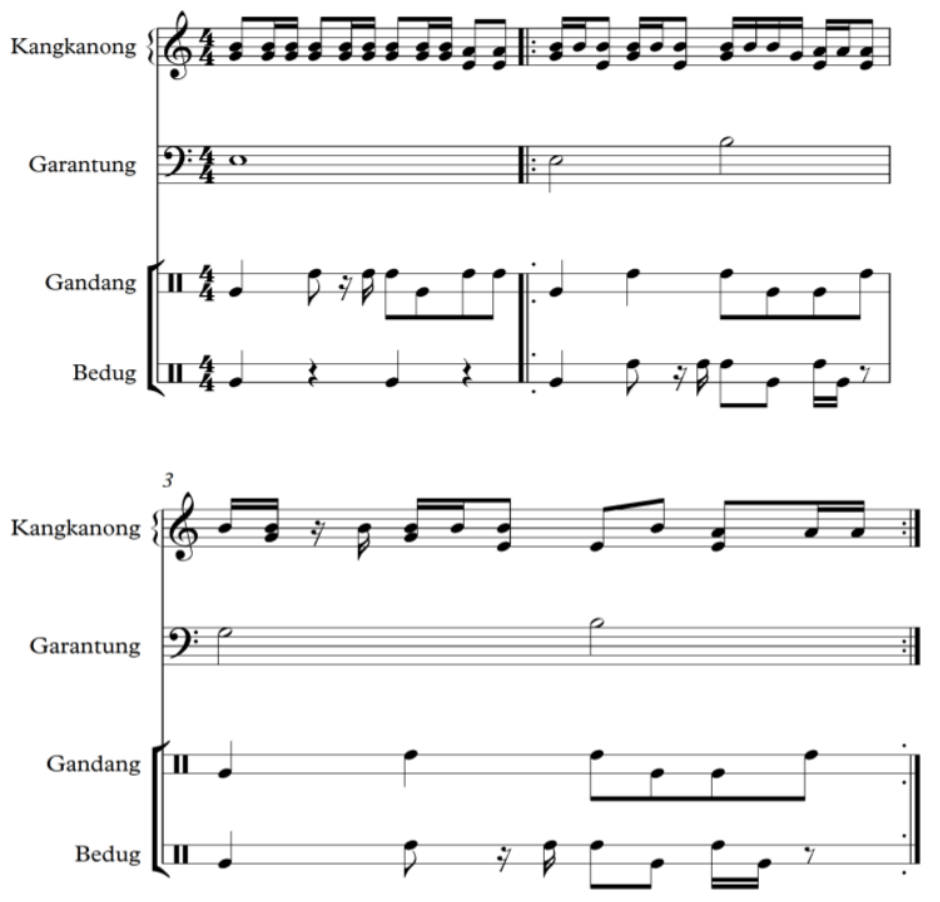

\section{7) Memperlihatkan}

Kedua

\section{Mempelai Pengantin}

Setelah keduanya sudah dipertemukan maka para dayang-dayang akan memperlihatkan keduanya kepada khalayak umum atau tamu undangan yang hadir pada saat berlangsungnya prosesi upacara Panganten haguet. Setelah keduanya sudah diperlihatkan, maka para dayang-dayang akan mengantarkan kembali kedua mempelai tersebut untuk menempati singgahsana yang sudah di siapkan untuk keduanya.

\section{8) Pembacaan Surat Pernikahan} (ijab kabul)

Tahapan terakhir pada prosesi upacara panganten haguet yaitu dilakukannya prosesi pembacaan surat pernikahan yang akan disaksikan oleh mantir adat dan kedua saksi dari setiap perwakilah masing-masing mempelai yang sudah ditentukan oleh kedua belah pihak keluarga mempelai. Kemudian setelah pembacaan surat pernikahan sudah selesai, maka kedua mempelai telah dinyatakan sah menjadi suami istri secara adat pernikahan suku Dayak Ngaju.

\section{Aspek Musikal}

\section{A. Ansambel Sakepeng \\ 1) Garantung}

Secara etimologi, instrumen garantung tidak memiliki penamaan khusus terhadap instrumen tersebut. Akan tetapi dari hasil wawancara yang didapat, munculnya penamaan pada 
instrumen garantung disebabkan dari adanya unsur bunyi yang dihasilkan dari badan instrumen tersebut pada saat ditabuh (pukul) atau dalam etnomusikologi disebut anamatopea.

Klasifikasi Sachs-Hornbostel, pada dasarnya mengelompokan instrumen musik ada empat kategori yaitu, idiofon, membranofon, kordofon, dan aerofon. Pengelompokan ini semestinya tidak dilihat sebagai pengelompokan yang mengimplikasikan hubungan genetik. Keberadaan instrumen garantung di pulau Kalimantan menurut buku yang di tulis oleh Haryanto, diduga bahwa keberadaan instrumen garantung didatangkan luar Kalimantan, hal ini disebabkan karena tidak pernah ditemukan tempat peleburan perunggu atau besalen (bahasa Jawa) dipulau ini. Gong-gong tersebut dimungkinkan didapat dengan cara barter, yaitu dengan cara menukarkan dengan hasil tambang dan hasil hutan seperti emas, kayu gaharu, sarang burung, dan lain sebagainya.

\section{2) Gandang Manca}

Secara etimologi, instrumen gandang manca memiliki dua suku kata yaitu gandang dan manca yang mengartikan bahwa Gandang itu adalah gendang, dan manca yang berarti dua membran, dengan kata lain gandang manca adalah gendang yang memiliki dua membran, dan instrumen ini hanya dimainkan pada saat proses upacara pernikahan dan kegiatan pancak silat. Gandang manca merupakan instrumen pukul yang menghasilkan sumber bunyi melalui selaput yang telah direntangkan, dan apa bila diklasifikasikan instrumen tersebut masuk pada golongan membranophones.

\section{3) Bedug}

Menurut kamus besar bahasa Indonesia, instrumen bedug merupakan gendang dengan bentuk ukuran yang cukup besar, biasanya instrumen tersebut digunakan untuk memberi tanda pada saat ingin melakukan salat di masjid. Kehadiran instrumen bedug merupakan pelangkap dari pada ansambel sakepeng, berdasarkan histori alat musik tradisional Dayak, bedug tidak termasuk sebagai salah satu instrumen Dayak, namun pada masa sekarang intensitas kehadiran bedug semakin sering dijumpai di acara-acara kesenian maupun ritual, salah satunya pada upacara adat pernikahan suku Dayak ngaju. Klasifikasi instrumen bedug dapat digolongkan pada sistem sumber bunyi membranophones, suara 
bedug yang keluar dihasilkan dari pada selaput atau membran (kulit) dengan cara direntangkan.

\section{4) Kangkanong}

Kangkanong adalah sebuah alat musik yang berbentuk seperti gong kecil yang biasa dikenal dengan nama kenong. Setiap perangkat kangkanong terdiri atas lima sampai tujuh buah, masing-masing dari satuan memiliki nada-nada yang berbeda. Setiap bilah dari satuan kangkanong diletakan pada sebuah stand yang berbentuk persegi panjang yang telah diberi tali dua baris memanjang, tujuan dari kotak tersebut sebagai resonansi.

\section{Klasifikasi instrumen kangkanong} digolongkan pada idiophones, sumber bunyi yang dihasilkan berasal dari badan instrumen tersebut, biasanya terbuat dari bahan padat seperti kayu, logam, dan lain sebagainya baik yang keras maupun elastik, yang dapat berbunyi tanpa bantuan membran.

Menurut Haryanto dalam bukunya menjelaskan bahwa instrumen kangkanong memiliki dua buah tangga nada yaitu pentatonik hemitonik dan pentatonik anhemitonik mirip seperti gamelan Jawa yang dikenal sebagai tangga nada pelog dan slendro. Tangga nada pentatonik anhemitonik dan pentatonik hemitonik dapat dilihat pada susunan nada dalam alat musik kanong atau kangkanong. Tangga nada yang digunakan dalam alat musik gong atau garantung yang masih lengkap berjumlah lima buah yaitu A-C-D-E-G.

\section{B. Notasi Pola Permainan.}

Tangga nada yang digunakan pada ansambel sakepeng adalah la do re mi sol, yang merupakan tangga nada pentatonis dengan meminjam istilah pada musik barat. Dalam hal ini motif yang terdapat pada ansambel sakepeng merupakan motif yang sederhana adapun penjelasan tentang motif tersebut terdapat pada kamus musik. Motif adalah bagian terkecil dari satuan kalimat lagu, baik berupa kata, suku kata, atau anak kalimat yang dikembangkan. Motif lagu akan selalu berulang sepanjang lagu, sehingga lagu yang terpisah atau tersobek dapat dikenali ciri-cirinya melalui motif tertentu. Dalam hal ini motif permainan yang terdapat pada musik ansambel sakepeng merupakan motif yang sederhana, dan sering kali dimainkan dengan cara diulang-ulang atau monoton. Adapun penjelasan yang lebih terperinci tentang musik ansambel sakepeng. Notasi sebagai berikut:. 
Pola Tabuhan Musik Sakepeng, tempo 100 dengan sukat 3/4.

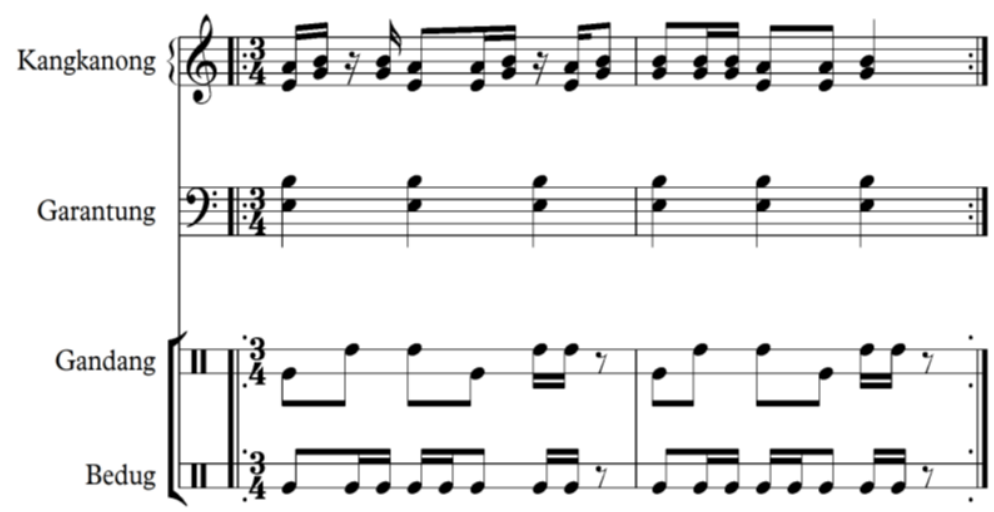

\section{Analisis Motif.}

1) Musik Sakepeng

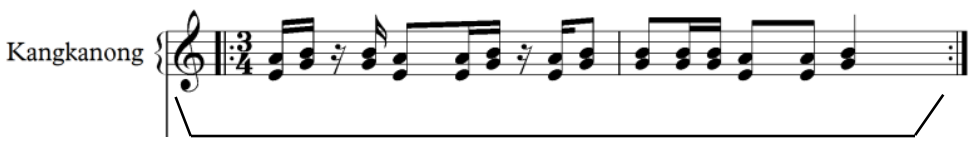

motif 1

Dalam permainan ansambel sakepeng pola melodi seperti di atas yang terdiri dari satu motif dimainkan oleh instrumen kangkanong secara berulang-ulang dengan menyesuaikan gerakan para pesilatnya. Permainan garantung menekankan dalam ritmis melodisnya yang memainkan interval kwart dalam setiap tabuhannya. Instrumen gandang dan bedug menekankan pada sisi ritmis yang dimainkan oleh ansambel itu. Hal tersebut juga berlaku dalam pola tabuhan musik bahalai 1 dan 2 . Tempo yang digunakan pada pola iringan musik sakepeng adalah 100 dengan sukat 3/4, sedangkan untuk pola iringan musik pada tari bahalai 1 dan 2 menggunakan tempo 100 dengan sukat $4 / 4$.

\section{Aspek Non Musikal. \\ Tempat}

Tempat pelaksanakan prosesi upacara pangantin haguet umumnya akan menyesuaikan pada tempat tinggal dari mempelai wanita, yaitu yang beralamatkan pada jalan Aries no. 48 perumahan Amaco Palangka Raya Kalimantan Tengah (rumah kediaman bapak Manca).

\section{Waktu}

Prosesi dilaksanakannya upacara panganten haguet umumnya menyesuaikan dengan waktu yang sudah disepakati oleh kedua belah pihak keluarga. Dalam hal ini prosesi arak-arakan yang berlangsung pada 
pukul 14.30 WIB merupakan proses awal dimulainya upacara panganten haguet.

\section{Sesajen}

Prosesi ritual yang diawali dengan pemutusan lawai sakepeng merupakan simbol dari hasil wujud representasi atas pemaknaan masyarakat suku Dayak Ngaju bahwa lawai yang terpasang pada pintu gerbang sakepeng memiliki sebuah arti yang bermakna sebagai, contoh misalkan pada bagian lawai satu merupakan simbol dari kurangnya keharmonisan pada saat berumah tangga, lawai kedua mengambarkan suatu hubungan yang tidak baik diantara keduanya pada saat melakukan aktivitas berumah tangga, dan lawai ketiga menggambarkan sesuatu yang berhubungan dengan kematian atau maut. Apa bila dari ketiga lawai tersebut sudah terputus, maka terputuskanlah semua halhal yang bersifat negatif yang ingin mengganggu kehidupan dari kedua calon mempelai.

\section{Pelaku}

\section{Simpulan}

Hadirnya musik ansambel sakepeng dalam upacara panganten haguet bagi masyarakat suku Dayak Ngaju, merupakan suatu hal yang tidak dapat dipisahkan, selain menjadi musik iringan pada prosesi pemutusan
Mantir adat merupakan orang yang bertugas sebagai pemimpin terlaksananya upacara panganten haguet. Jumlah dari mantir adat hanyalah berjumlah dua orang yaitu, mantir satu mewakili pihak keluarga mempelai laki-laki, mantir dua bertugas mewakili pihak keluarga mempelai wanita. Keduanya berperan sebagai juru bicara dari masing-masing mempelai, terutama pada saat prosesi penyerahan syarat maskawin (nagih janji).

\section{Kostum}

Kostum yang dikenakan pemain sakepeng dan penari umumnya melibatkan unsur lima BA, yang berarti adalah lima warna, kata BA sendiri iyalah imbuhan awal pada penyebutan warna dengan menggunakan bahasa Dayak Ngaju contohnya Baputi berarti Putih, Babilem/Hitam Bahenda/Kuning, Bahandang/Merah, Bahijau/Hijau. Menurut masyarakat suku Dayak Ngaju lima BA merupakan lima warna yang sangat sakral, maka dari itu dalam pembuatan kostum ataupun ornamen sangat dipastikan akan ada unsur lima BA.

lawai, hadirnya musik ansambel sakepeng merupakan satu bagian terpenting atas terlaksanakannya upacara tersebut. Ansambel ini menjadi ciri khas dalam pesta pernikahan pada masyarakat Dayak Ngaju di Kalimantan Tengah. 
Adapun terdapat dua fungsi dalam pelaksanaan upacara panganten haguet yaitu fungsi primer (pertama) yang dimana meliputi sarana ritual, hiburan, dan sarana presentasi estetis. Fungsi sekunder (kedua) yang dimana meliputi sarana komunikasi dalam menyampaikan suatu pesan kepada suatu kelompok melalui media musik. Pada bentuk dan penyajian musik ansambel sakepeng dalam upacara panganten haguet terbagi menjadi dua bagian yaitu aspek musikal dan non musikal.

Ansambel musik sakepeng mengalami perkembangan sesuai dengan dinamika kehidupan masyarakat, adapun dalam hal ini terjadinnya penambahan alat musik yang hadir pada ansambel tersebut sebagai antisipasi dari perkembangan masyarakat Dayak Ngaju yang menginginkan musik tersebut menjadi lebih dinamis.

\section{E. Daftar Pustaka}

Bakar, Seth, Rangka Siren F, T.Andin Gani. 1991. Peralatan Hiburan Dan Kesenian Tradisional Daerah Kalimantan Tengah. Palangkaraya: Direktur Jenderal Kebudayaan Departemen Pendidikan Dan Kebudayaan.

Creswell, John W. 2015. Penelitian Kualitatif \& Desain Riset: Memilih di Antara Lima Pendekatan, Yogyakarta: Pustaka Pelajar.

Hadi, Y. Sumandiyo. 2006. Seni Dalam Ritual Agama. Yogyakarta: PUSTAKA.
Haryanto. 2015. Musik Suku Dayak Sebuah Catatan Perjalanan di Pedalaman Kalimantan. Yogyakarta: Badan penerbit ISI Yogyakarta.

Hendarto, Sri. 2011. Organologi dan Akustika I \& II. Bandung: Lubuk Agung.

Lumholtz, Carl. 1991. Through Central Borneo. New York: Oxford University Press.

Merriam, Alan P. 1964. The Anthropology of Music. Terj. Triyono Bramantyo

Northwestern: University Press.

Mihing, Teras, S.Rusan Ikel, Kunom Sylvanus, Uda M.Felix. 1994. Adat Dan Upacara Perkawinan Daerah Kalimantan Tengah. Palangkaraya: Direktur Jenderal Kebudayaan Departemen Pendidikan Dan Kebudayaan.

Penyang, Simal., et. Al. 1976. Panaturan dan Penerjemahannya. Palangkaraya: Majelis Besar Ulama Kaharingan Indonesia.

Prier, Karl Edmund SJ. 2015. Ilmu Bentuk Musik. Yogyakarta: Pusat Musik Liturgi.

Riwut, Tjilik. 2003. Maneser Panatau Tatu Hiang. Palangkaraya: PUSTAKALIMA.

Rousseau, Jerome. 1990. Central Borneo: Ethnic Identity and Social Life in a Stratified Society. New York: Oxford University Press.

Soedarsono, R. M. 2001. Metodologi Penelitian Seni Pertunjukan dan Seni Rupa. Bandung: Masyarakat Seni Pertunjukan Indonesia. . 2002. Seni Pertunjukan di Era Globalisasi. Yogyakarta: 
Gadjah Mada University press.

Senen, I Wayan. 2015. Bunyi-bunyian Dalam Upacara keagamaan Hindu Di Bali. Yogyakarta: Badan Penerbit ISI Yogyakarta.

Spradley, James P. 1997. Metode Etnografi (Penerjemah: Misbah Zulfa Elizabeth), Yogyakarta: PT. Tiara Wacana Yogya.

Sugiyono. 2012. Metode Penelitian Kuantitatif, Kualitatif dan $R \& D$. Bandung: Alfabeta Bandung.

\section{NARASUMBER}

Cornelis Pith, 58 tahun, Mantir Adat Keluharan Menteng, Palangkaraya, Kalimantan Tengah.
Jimy Oktolongere Andin, S.Sn., M.Pd pemilik sanggar seni budaya Tut Wuri Handayani Palangka Raya, Kalimantan Tengah.

Kristopel S. Kusin, 50 tahun, Mantir Adat Keluharan Langkai, Palangkaraya, Kalimantan Tengah.

Rabiadi, 42 tahun, Basir Upu Kelurahan Langkai, Palangkaraya, Kalimantan Tengah.

Rumsoe Sanggah, 72 tahun, Mantir Adat Kelurahan Jekan Raya, Palangkaraya, Kalimantan Tengah. 